$\$=-$ 原

\title{
Numerical modeling of safety factor evaluation associated with the dredging and quarry mining techniques in northeast Bangladesh
}

\author{
Md. Rafiqul Islam*, Mohammed Omar Faruque, Abu Toyob Shahid, Iqbal Hossain, Abdullah Al Masum \\ Department of Petroleum \& Mining Engineering Shahjalal University of Science \& Technology, Sylhet 3114, Bangladesh \\ *Corresponding author E-mail: dmrislam74@gmail.com
}

\begin{abstract}
This article describes the numerical modeling to investigate the safety factor of the quarry and dredging mining methods in the Volagonj area of Sylhet district in northeast Bangladesh. Two kinds of numerical models (A and B) are presented here. Both models consist of a single zone that includes gravelly sand deposits with some fine silt and clay. The zone also bears homogeneous rock/soil physical characteristics. Model A assumes safety factor of dredging mining method with variable slope angles and water column height of $40 \mathrm{~m}$. Model $\mathrm{B}$ assumes safety factor of the quarry mining method associated with variable slope angles, where water column of the riverbed has not been considered. The numerical modeling results reveal that the safety factor of the model A ranges from 1.56 to 1.04 . The safety factor ranges from 1.32 to 0.81 for model B. The calculated safety factor of the Volagonj rock quarry implies that the slope angle should not be greater than $70^{\circ}$ for the dredging mining method. Because the critical safety factor values are 1.07 and 1.04 associated with slope angles $75^{\circ}$ and $80^{\circ}$, respectively. For the case of the quarry mining, the appropriate slope angle also should not be greater than $60^{\circ}$.
\end{abstract}

Keywords: Dredging and Quarry Mining Methods; Numerical Modeling; Safety Factor Analysis.

\section{Introduction}

Dredging mining is the mining of sediment deposited from flowing water, such as gravel, sand and rock. It is a type of alluvial mining that involves the use of a floating boat or barge with either a series of buckets to scoop gravel, or a suctioning apparatus to vacuum gravel from the bottom of a river. Quarrying is a type of surface mining from which rocks are extracted for utilizing building materials, like dimension stone. Quarries are normally shallower than other kinds of open-pit mines. It is reasonable to mention that a quarry is a big man-made hole in the ground from where rock are taken out. Quarries are made when big deposits of commercially helpful minerals or rock are found close to the Earth's surface (http://www.greatmining.com/quarrying.html).

Assessments of the safety factor of pit slopes are the most important aspects in surface mining, for example, in dredging and quarry mining (Islam \& Faruque 2013a). Recently, there has been adequate development in the computer-aided programs for the safety factor analysis. Numerical modeling of rock slopes safety factor is now used routinely in the mining engineering sectors as well as in academic research. The use of limit equilibrium methods still remains the most common adopted solution method in surface rock/soil engineering (Stead \& Eberhardt 1997, Stead et al. 2006, Daftaribesheli et al. 2011, Kulatilake et al. 2011, Ning et al. 2011).

Volagonj rock quarry of Sylhet district (Figs. 1and 2) is the largest hard-rock quarry in northeast Bangladesh. Two types of mining methods have been used here since 2006. The first one is called the qaurry mining, which is used in the dry season (from November to April) of the year and the second one is the dredge mining method, which is applied in the rainy season (from May to the end of October) of the year. The height of the riverbed water column of the study area was measured up to $40 \mathrm{~m}$ in the rainy season (May to October). Kinds of rock that are being extracted from the Volagonj quarry comprised of construction aggregates- like sand gravels, pebble, cobble and boulders of granite, limestone and sandstone.

Both mining methods- like quarry and dredging frequently have particular engineering problems associated with safety factor of the slope, which is affected seriously in both the dry and rainy seasons. The major purpose of the present study is to evaluate the safety factor of pit slope associated with quarry and dredging mining techniques in the Volagonj area of northeast Bangladesh. The modeling results highlight the safety factor associated with variable slope angles by considering the numerical modeling.

\section{Geology of the study area}

A generalized stratigraphic succession of north-eastern Bangladesh and India (from the Recent to Pliocene age) is as follows. Lower Level Alluvium of the recent age, that consists of sand, silt and clay. Older Alluvium of Middle to Upper Pleistocene age which is composed of sand, clay, pebble, gravel and boulder deposit. Dihing Formation ( $900 \mathrm{~m}$ ) of Dihing Group of Pliocene age 


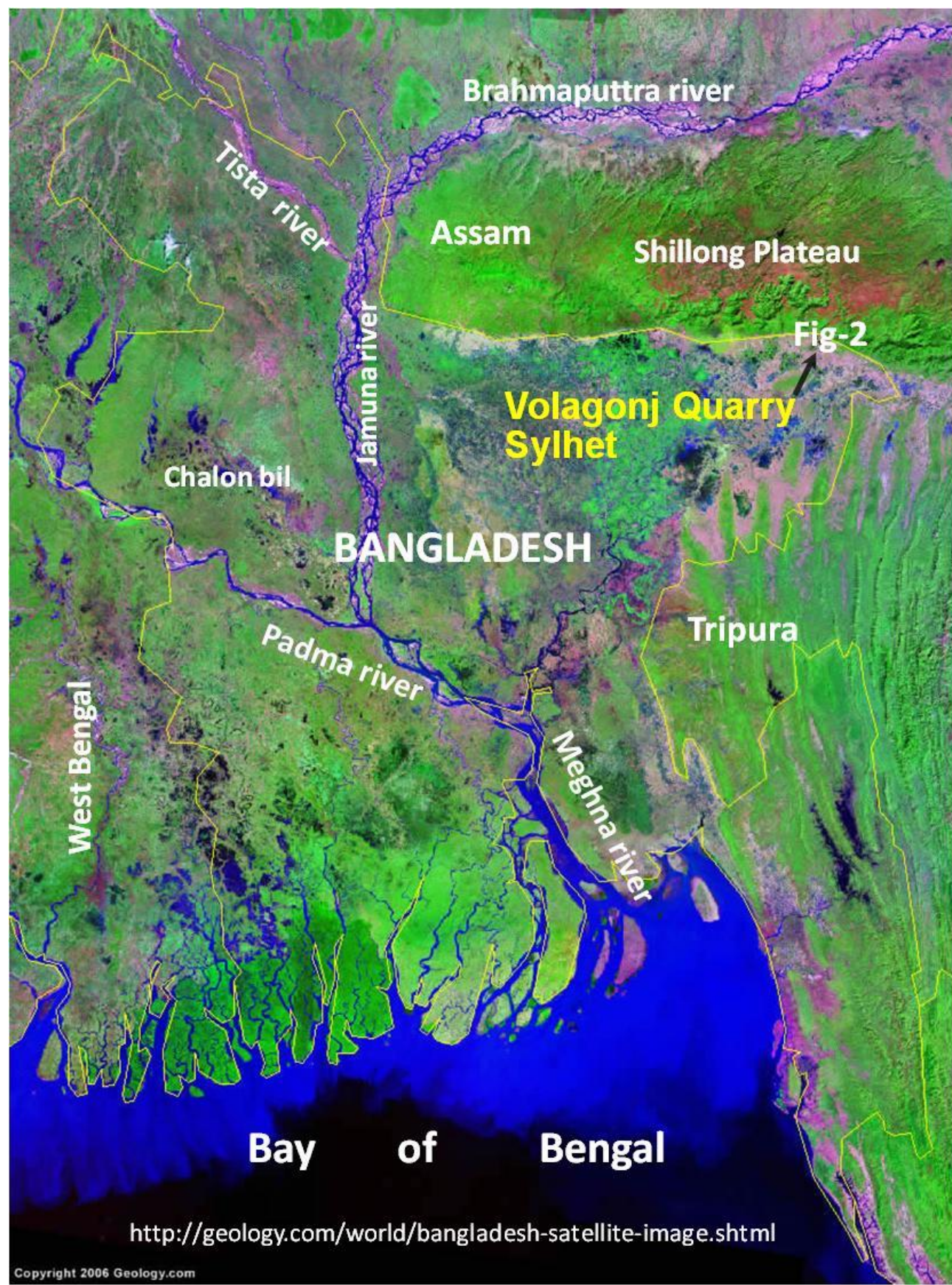

Fig. 1: Location of the Volagonj Rock Quarry, Sylhet, Bangladesh (Source: Http://Geology.Com/World/Bangladesh-Satellite-Image.Shtml).

that comprising of pebble beds, soft sandy clay, clay, conglomerate, grit, gravel and sandstone (Islam \& Faruque 2013b). The mining rock source in the Volagonj area is the Dihing Group of Pliocene age.

\section{Mining depth, size range of aggregates and slope angles}

Direct field investigation was carried out to collect samples, measure the slope geometry of the pit and the riverbed water column height. The analysis of sediment samples collected from the Volagonj quarry show that the texture is predominantly sandy, and the grain size varies from fine to coarse. The rock samples that were collected to a depth of $40 \mathrm{~m}$ below the riverbed show the presence of Gravels (16-32 mm diameter), Pebbles (32-64 mm diameter), Cobbles (64-256 mm diameter), and Boulders (>256 $\mathrm{mm}$ diameter). The overall side slope for both mining methods was usually ranging between $55^{\circ}$ to $70^{\circ}$ (Fig.3).

\section{Numerical modeling}

In the present study, finite element method (FEM) numerical modeling has been applied to calculate the factor of safety that lead to the stability of the slope angle of the Volagonj quarry. We applied the software package SLIDE (www.rocscience.com) to analyze the safety factor associated with the two steps of modeling, such as - (i) model with water column effect that emphasized the slope stability for dredging mining method in the rainy season (May to end of October), and (ii) model without water column effect that emphasized the slope stability for the quarry mining method in the dry season (November to April). The calculation of the safety factor has been preferred to assess the optimum slope angle for both the quarry and dredging mining methods. Calculated slope angles were $55^{\circ}, 60^{\circ}, 65^{\circ}, 70^{\circ}, 75^{\circ}$, and $80^{\circ}$, respectively. 




Fig. 2(A-B): (A) Panoramic view of the Volagonj rock quarry, (B) Location of deposits, where dredging mining in the rainy season is going on.

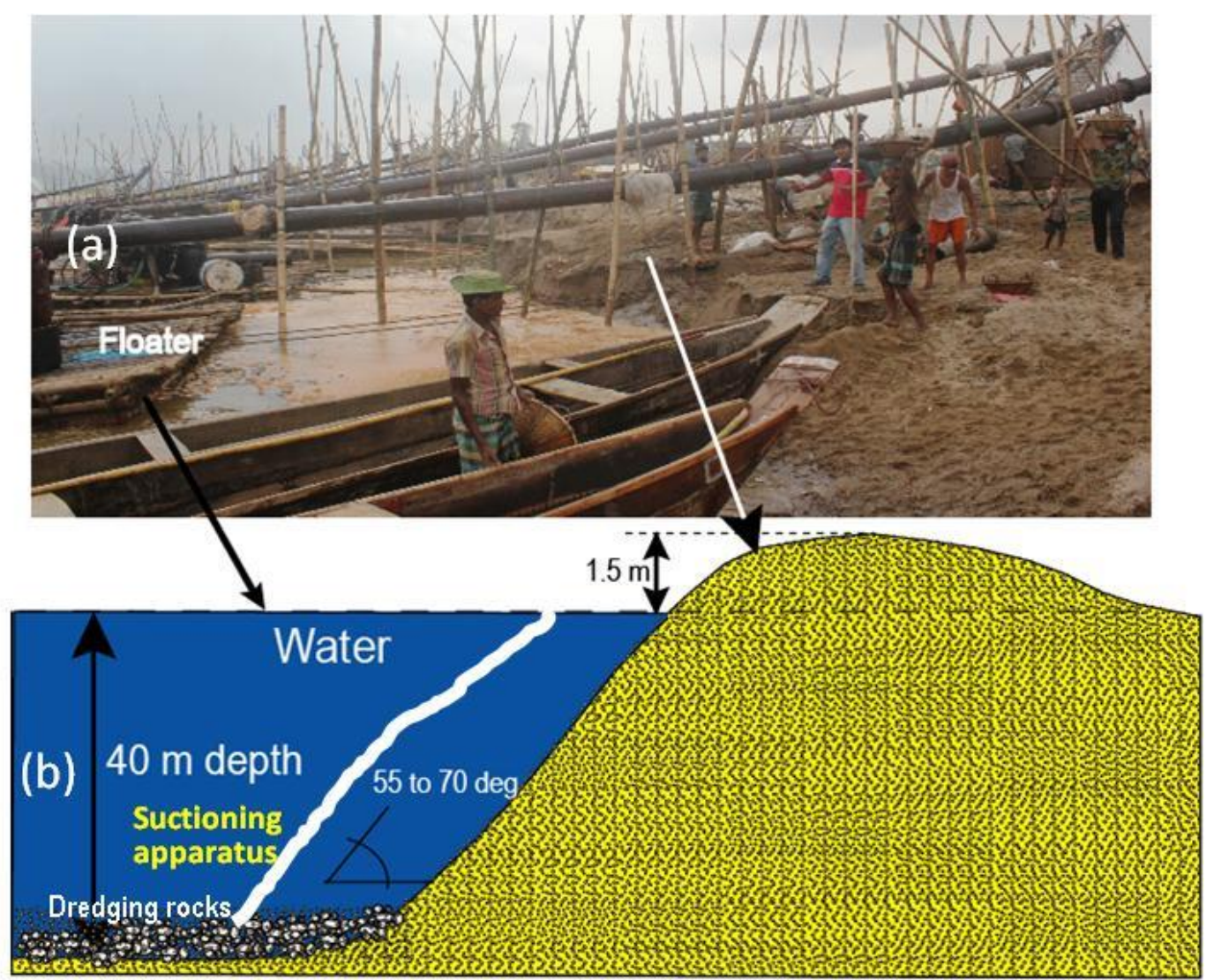

Fig. 3(A-B): (A) Boats/Floaters are using to keep stable of the suctioning apparatus, (B) Applied slope angles that range from 55 to 70 degrees.

\subsection{Model geometry, material properties and boundary conditions}

Two types of finite element (FE) model geometry, like- model A and model B is given in Figs. 4ab. Model A considers the dredging mining method in the rainy season, where $40 \mathrm{~m}$ of water column with variable slope angles $\left(55^{\circ}\right.$ to $\left.80^{\circ}\right)$ have been applied. Model B considers the quarry mining method in the dry season, where water column height has not been considered. The saturated unit weight of well graded gravel, sandy gravel, with little or no fines gravelly sand is $22 \mathrm{kN} / \mathrm{m}^{3}$, where the dry unit weight is 20
$\mathrm{kN} / \mathrm{m}^{3}$. Friction angle of well graded gravel, sandy gravel, with little or no fines rangres from 33 to 40 degrees, where cohesion is almost zero. Cohesion is about 40 to $50 \mathrm{kN} / \mathrm{m}^{2}$ with some clay and fine silts sediments (Koloski et al. 1989). The saturated unit weight of the model was $22 \mathrm{kN} / \mathrm{m}^{3}$. The position of water column in the model is shown in Fig. 4a. 


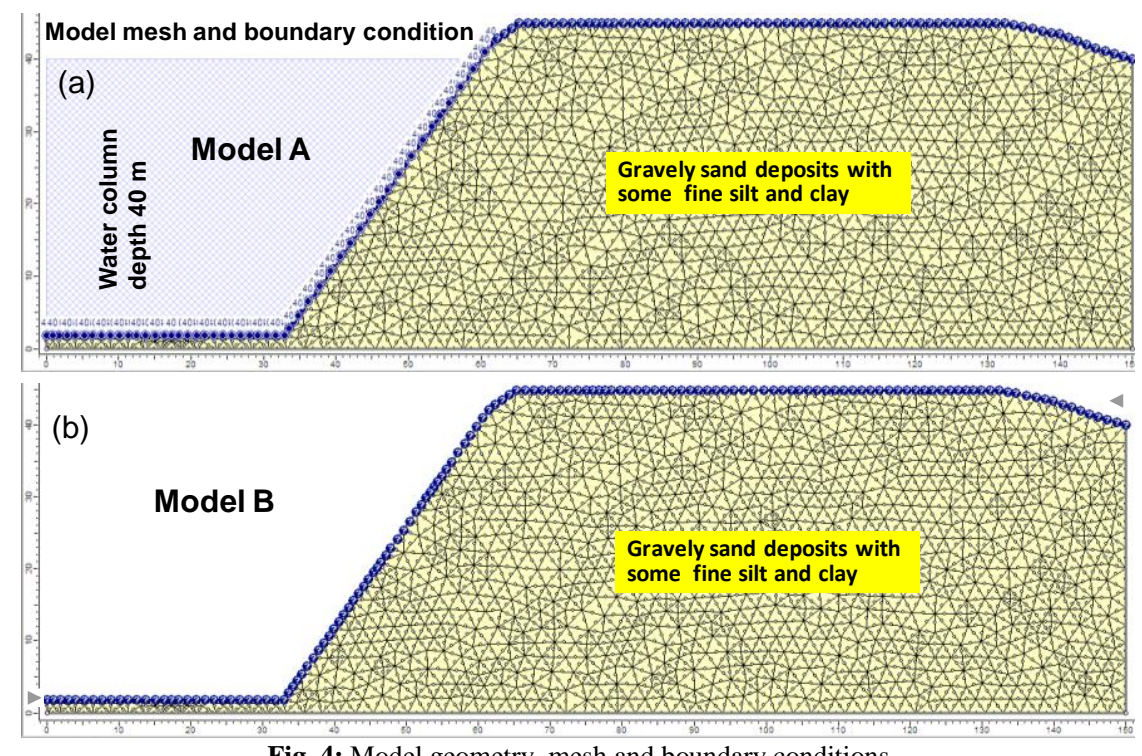

The pore fluid unit weight is $9.81 \mathrm{kN} / \mathrm{m}^{3}$. Since the model is a surface excavation model, the ground surface is a free surface. Triangular markers (Fig. 4b) at the left and right sides of the free surface indicate slope limits. All nodes at the base, left side, and right side boundary are given a fixed, zero displacement boundary condition

\section{Modeling results}

The numerical modeling results are presented in terms of a safety factor associated with variable slope angles. The measured slope angles of the models were $55^{\circ}, 60^{\circ}, 65^{\circ}, 70^{\circ}, 75^{\circ}$, and $80^{\circ}$. Figs. 5 (a-f) represent a safety factor of slope of the model A. For the case of model $\mathrm{A}$, the calculated safety factors were $1.56,1.50$, $1.43,1.45,1.07$ and 1.04 associated with the slope angles of $55^{\circ}$, $60^{\circ}, 65^{\circ}, 70^{\circ}, 75^{\circ}$ and $80^{\circ}$, respectively. Figs. 6(a-f) represent a safety factor of slope of the model $\mathrm{B}$, where the safety factors were $1.32,1.25,1.17,1.15,0.85$ and 0.81 for the slope angles of $55^{\circ}, 60^{\circ}, 65^{\circ}, 70^{\circ}, 75^{\circ}$ and $80^{\circ}$, respectively.

\section{Discussions and conclusions}

Quarry mining from the Volagonj is preferred since it is shallow and is of low priority reach. The stability of slope has been calculated both in static water condition (model A) and without water (model B). The safety factor analysis has been carried out by using Slide software package. In Slide, the overall geology is defined, including the material properties. Material above the slope surface is ignored. The stability of slope is studied using Bishop simplified method of analysis incorporated in Slide. We have considered circular failure surfaces assuming that the material on the scale of the slope is non-cohesive, comparatively homogeneous and isotropic. The analysis is carried out at six critical stages considering different slope angles, like- $55^{\circ}, 60^{\circ}, 65^{\circ}, 70^{\circ}, 75^{\circ}$ and $80^{\circ}$. Scholarly literatures reveal that safety factor 1.5 along a slope indicates usually a high safety factor against slope failure. The safety factor 1.25 indicates marginal factor of safety for a permanent slope with a high consequence of failure. If the value is almost 1 , this indicates that the slope is close to failure (Wyllie \& Mah 2005, p. 115) We started our modeling calculation with $55^{\circ}$ slope angle, where the safety factor was almost 1.56 (Fig. 5a). Subsequently, the slope angle was increased gradually up to $80^{\circ}$, and the safety factor was also decreased progressively. So, the numerical modeling results indicate that increased slope angle results in decrease in factor of safety and increased rock/soil fall problems.

Considering the existing $40 \mathrm{~m}$ height water column in the riverbed system, as applied in model A, the suitable slope to be maintained from $55^{\circ}$ to $70^{\circ}$ during dredging mining method, where the factor of safety ranges from 1.56 to 1.45 . Therefore, it is reasonable to mention that the slope angle should not be greater than $70^{\circ}$ because the critical safety factor values are 1.07 and 1.04 (as shown in Figs. 5ef) for slope angles $75^{\circ}$ and $80^{\circ}$, respectively. Scholarly literatures reveal that if a safety factor of the slope at the moment of failure is unity, it implies critical failure (Zhang et al. 2010). For the case of quarry mining method, as applied in model B, the suitable slope angle also should not be exceeded to $60^{\circ}$, for which the calculated safety factor value is 1.25 . The present study also highlights that water pressures, especially riverbed water column could play a significant role to control the safety factor of slope for dredging mining method. 




Fig. 5 (A-B): Safety factors for the Model A associated with slope angles of (A) $55^{\circ}$, (B) $60^{\circ}$
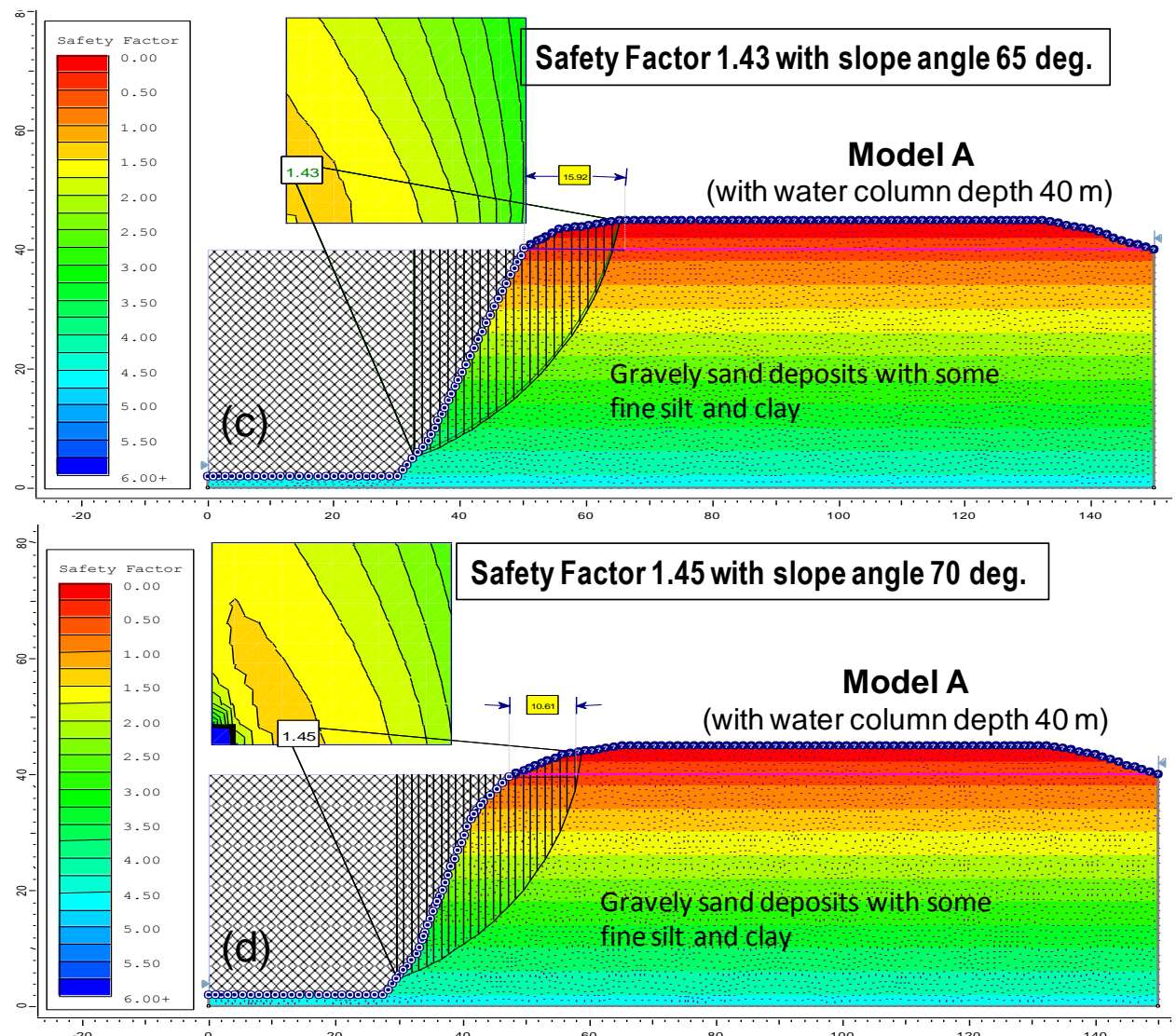

Fig. 5 (C-D): Safety factors for the Model A associated with slope angles of (C) $65^{\circ}$, (D) $70^{\circ}$ 


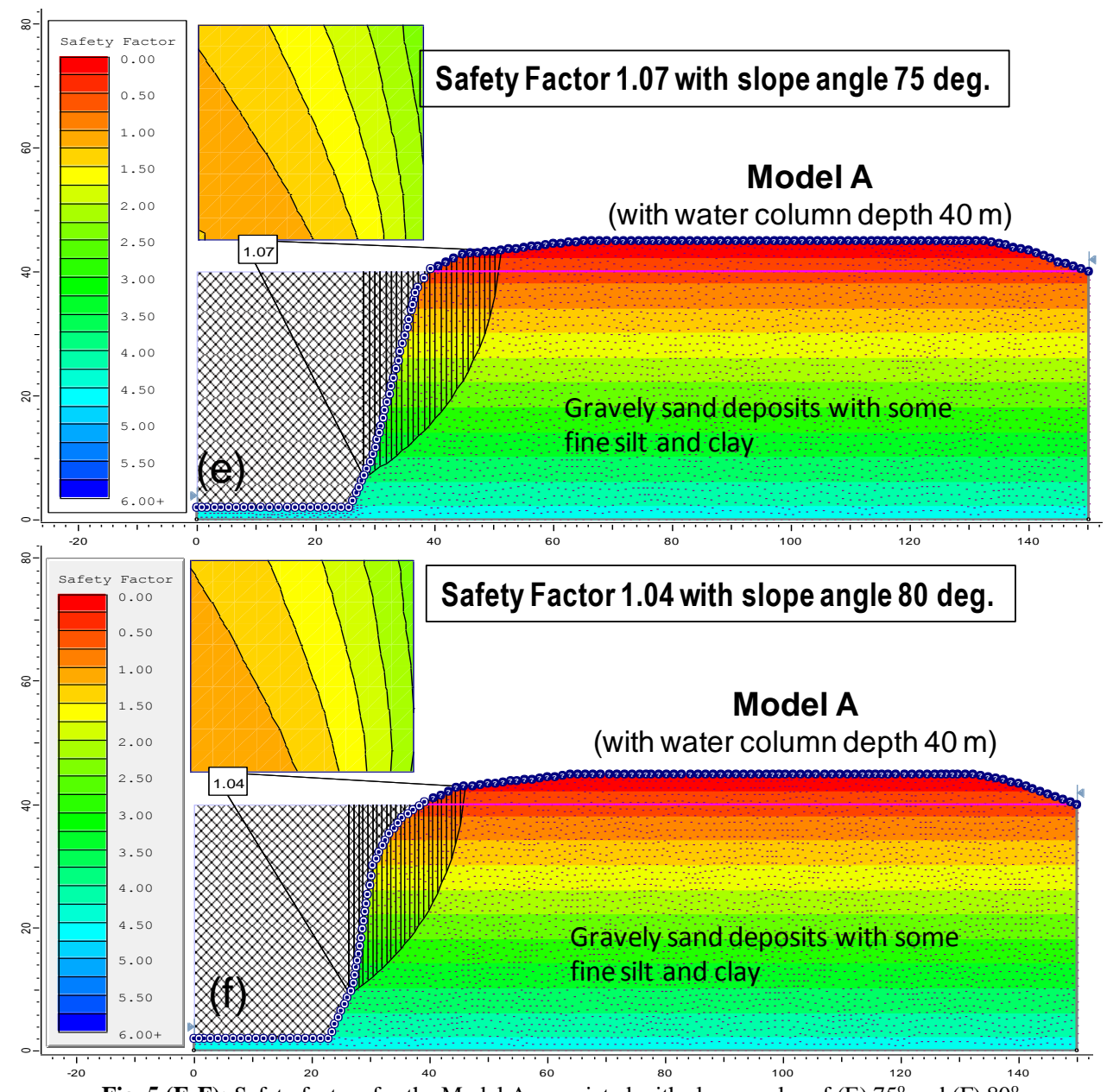

Fig. 5 (E-F): Safety factors for the Model A associated with slope angles of (E) $75^{\circ}$ and (F) $80^{\circ}$

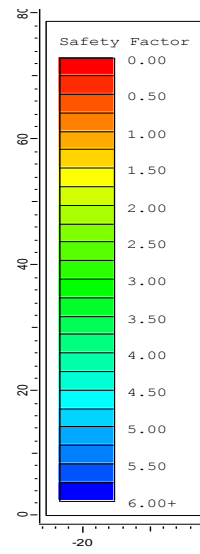

(a)
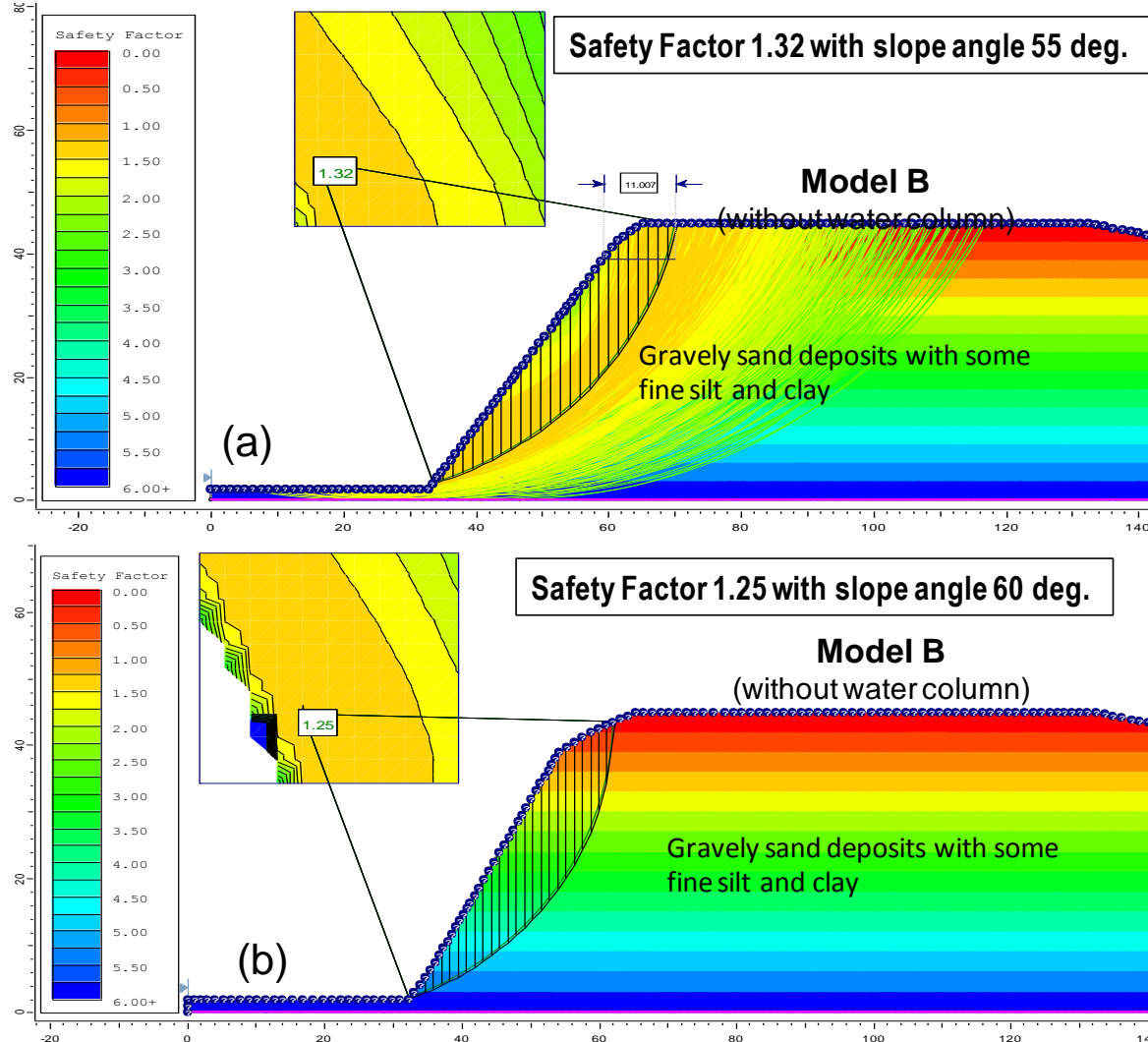

Model B

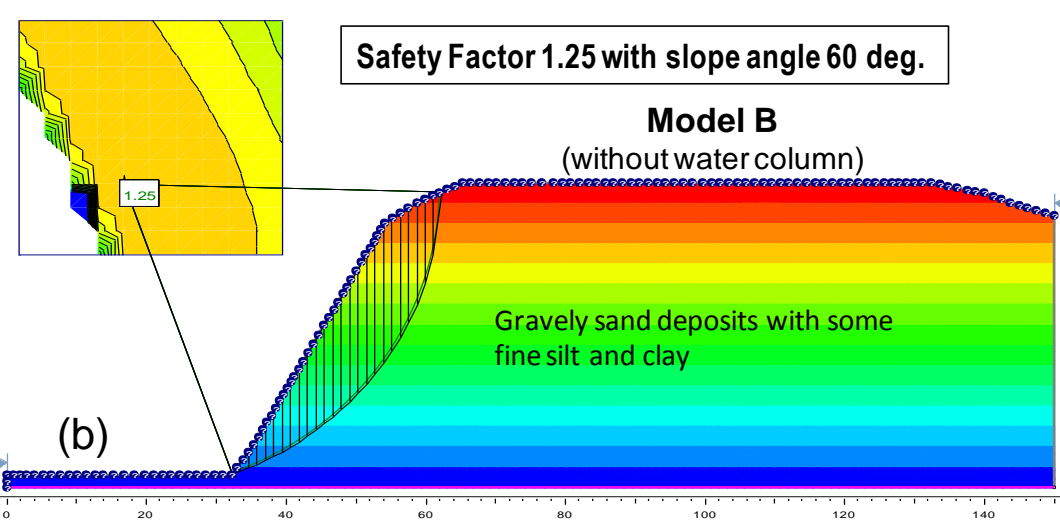

Fig. 6 (A-B): Safety factors for the Model B associated with slope angles of (A) $55^{\circ}$, (B) $60^{\circ}$ 


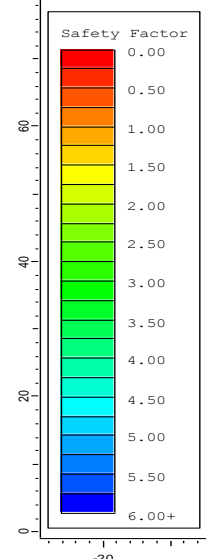

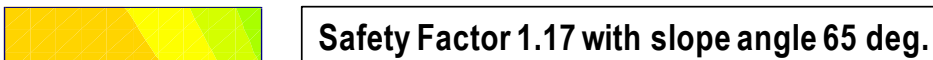

Model B

(withoutwater column)
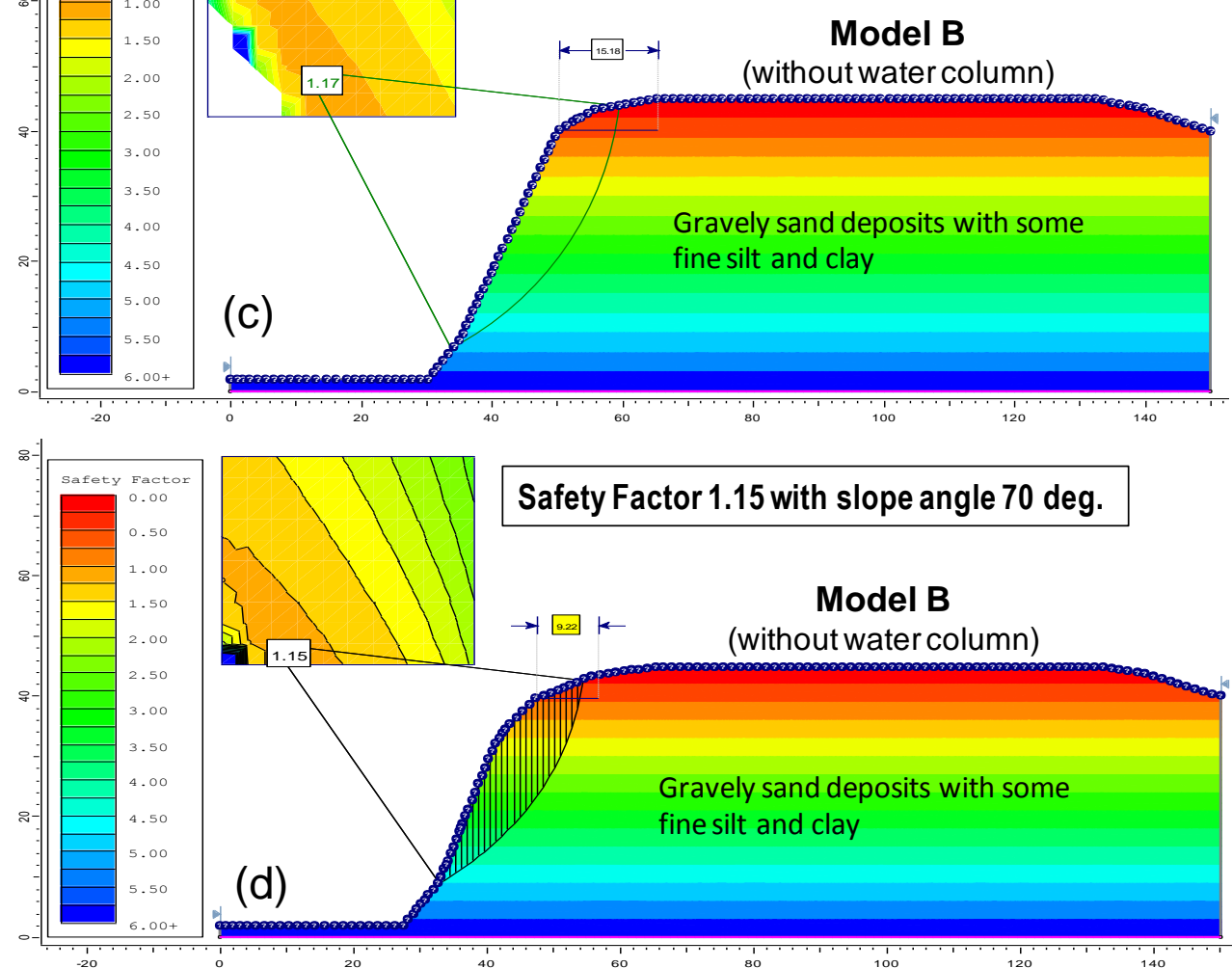

Fig. 6 (C-D): Safety factors for the Model B associated with slope angles of (C) $65^{\circ}$, and (D) $70^{\circ}$


Fig. 6 (E-F): Safety factors for the Model B associated with slope angles of (E) $75^{\circ}$ and (F) $80^{\circ}$ 


\section{References}

[1] Daftaribesheli A, Ataei M, Sereshki F 2011. Assessment of rock slope stability using the Fuzzy Slope Mass Rating (FSMR) system. Applied Soft Computing, 2011, 11: 4465-4473. http://dx.doi.org/10.1016/j.asoc.2011.08.032.

[2] Islam MR. Faruque MO 2013a. Optimization of Slope Angle and Its Seismic Stability: A Case Study for the Proposed Open Pit Coalmine in Phulbari, NW Bangladesh. Journal of Mountain Science, 2013, 10(6): $\quad 976-986 . \quad$ DOI: $10.1007 / \mathrm{s} 11629-012-2483-6$ http://dx.doi.org/10.1007/s11629-012-2483-6.

[3] Islam MR, Faruque MO 2013b. Seismic slope stability of the Tipaimukh Dam of north-eastern India: A numerical modeling approach. Earth Sciences, 2013, 2(3):73-87. doi 10.11648/j.earth.20130203.12 http://dx.doi.org/10.11648/j.earth.20130203.12.

[4] Koloski JW, Schwarz SD, Tubbs DW 1989. Geotechnical Properties of Geologic Materials, Engineering Geology in Washington, Volume 1, Washington Division of Geology and Earth Resources Bulletin, 1989. 78.

[5] Kulatilake PHSW, Wang L, Tang H, Liang Y 2011. Evaluation of rock slope stability for Yujian River dam site by kinematic and block theory analyses. Computers and Geotechnics, 2011, 38: 846-860. http://dx.doi.org/10.1016/j.compgeo.2011.05.004.

[6] Ning YJ, an XM, Ma GW 2011. Footwall slope stability analysis with the numerical manifold method. International Journal of Rock Mechanics \& Mining Sciences, 2011, 48:964-975. http://dx.doi.org/10.1016/j.ijrmms.2011.06.011.

[7] Stead D, Eberhardt E. 1997. Developments in the analysis of footwall slopes in surface coal mining. Engineering Geology, 1997, 46:41-61. http://dx.doi.org/10.1016/s0013-7952(96)00084-1.

[8] Stead D. Eberhardt E, Coggan JS 2006. Developments in the characterization of complex rock slope deformation and failure using numerical modelling techniques. Engineering Geology 2006; 83: 217- 235. http://dx.doi.org/10.1016/j.enggeo.2005.06.033.

[9] Wyllie DC, Mah CW 2005. Rock Slope Engineering, Civil and Mining. Spon Press, 270 Madison Avenue, New York, NY 10016, 2005. p. $109-151$

[10]Zhang LL, Zhang J, Zhang LM, Tang WH 2010. Back analysis of slope failure with Markov chain Monte Carlo simulation. Computers $\begin{array}{lll}\text { and } \quad \text { Geotechnics, 2010, 37:905-912. } & \text {. }\end{array}$ http://dx.doi.org/10.1016/j.compgeo.2010.07.009. 